\title{
Effects of Pathogen Population Levels and Crop-Derived Nutrients on Development of Soybean Sudden Death Syndrome and Growth of Fusarium virguliforme
}

\author{
Gretchen M. Freed, Crystal M. Floyd, and Dean K. Malvick, Department of Plant Pathology, University of Minnesota, St. Paul 55108
}

\begin{abstract}
Sudden death syndrome (SDS) of soybean, caused by Fusarium virguliforme, is a significant disease of soybean. The suite of factors that influence disease development is incompletely understood. The goal of this study was to determine the effects of pathogen population levels, crop residues, seed exudates, and their interactions on development of SDS and growth of $F$. virguliforme. Studies were conducted in a greenhouse with cultivars susceptible and partially resistant to SDS, four pathogen population levels, and six crop residue treatments (none; ground corn seed, stalks, and roots; ground soybean stems; and sorghum seed). Root rot was assessed 15 and 50 days after inoculation (dai) and foliar disease and plant biomass were assessed 50 dai. Population level increases and crop residues had significant interacting effects on increasing foliar

disease severity and root rot and on biomass reduction. Disease severity was positively correlated with population and biomass was negatively correlated. Plants grown with no crop residues exhibited low or no root rot or foliar disease 15 dai, and severity was greatest with corn and sorghum seed. In vitro studies were conducted to test the effects of exudates collected from germinating soybean and corn seed on growth of $F$. virguliforme and $F$. solani. Growth of these fungi was greater in exudates than in water. More growth occurred in exudates collected during soybean radicle emergence than those sampled at other times during germination. These studies show that pathogen population levels and crop-derived nutrients in soil interact and influence severity of SDS. Results have implications for gaging disease risk and managing SDS.
\end{abstract}

Sudden death syndrome (SDS) is one of the most destructive diseases of soybean (Glycine max (L.) Merr.) in North and South America (Hartman et al. 2015a,b; Roy et al. 1997). The causal agent of SDS is the soilborne fungus Fusarium virguliforme in North America, and this is one of several Fusarium spp. causing SDS in South America (Aoki et al. 2003; O'Donnell et al. 2010). Management of SDS has chiefly relied on the use of soybean cultivars with resistance; and fungicide seed treatments have recently shown efficacy (Hartman et al. 2015b). Although crop rotation is effective for managing many soilborne diseases, it has not been consistently effective for managing SDS (Hartman et al. 2015a,b; Roy et al. 1997; Rupe et al. 1997). For example, the soybean-corn rotation does not reduce SDS, and corn may support survival of $F$. virguliforme (Kolander et al. 2012; Xing and Westphal 2009).

The SDS disease cycle requires early- and late-season activity by $F$. virguliforme for the disease to fully develop (Gongora-Canul et al. 2012; Gray and Achenbach 1996; Kazi et al. 2008; Navi and Yang, 2008; Roy et al. 1997). Infection of young roots by F. virguliforme can occur soon after seed germination, and appears to be important for development of high foliar disease severity (Gongora-Canul and Leandro 2011; Navi and Yang 2008; Roy et al. 1997). The radicle of soybean seedlings generally emerges a few days after initiation of seed imbibition and, soon after this time, $F$. virguliforme can penetrate and colonize the xylem tissues (Lersten and Carlson 2004; Navi and Yang 2008). The fungus then appears to develop slowly until the host's reproductive growth stages, when more root rot develops and phytotoxins produced by the pathogen are translocated to the leaves and result in chlorosis and necrosis (Chang et al. 2016; Hartman et al. 2015a; Jin et al. 1996; Pudake et al. 2013). If the root is infected after the very young stage, fungal colonization appears to be limited to the cortical and phloem tissue and only low levels of foliar symptoms may develop (Gongora-Canul and Leandro 2011; Navi and Yang 2008).

Corresponding author: D. Malvick; E-mail: dmalvick@umn.edu

Accepted for publication 27 October 2016.

() 2017 The American Phytopathological Society
Factors that influence development of SDS are known to include soil moisture, temperature, susceptibility of the soybean cultivar, and soybean cyst nematode ( $\mathrm{SCN}$ ) populations; however, many other factors that influence SDS are poorly understood (de Farias Neto et al. 2006; Hartman et al. 2015 a,b; Roy et al. 1997; Rupe at al. 1993; Westphal et al. 2014). One of the poorly understood factors is the soil population level of $F$. virguliforme. Several greenhouse studies suggest that populations of this pathogen may influence the development of SDS (Gongora-Canul et al. 2012; Gray and Achenbach 1996; Luckew et al. 2012; Njiti et al. 2001). For studies done of populations in soybean production fields where SDS had developed, dilution plating analysis of soil samples suggested a positive relationship between severity of SDS and inoculum density in symptomatic areas of fields (Roy et al. 1997; Rupe et al. 1997; Scherm et al. 1998).

Studies in microplots and greenhouses have further clarified some aspects of the relationships between soil population levels of $F$. virguliforme and SDS development. Many of the studies used inocula consisting of $F$. virguliforme-colonized sorghum seed or cornmeal (Gray and Achenbach 1996; Luckew et al. 2012). The results generally showed an increase in SDS severity as quantities of these colonized grain substrates increased, but the quantity of $F$. virguliforme was typically not determined. The addition of quantified macroconidia of $F$. virguliforme to soil in microplot studies has further illustrated the challenges and complexity of this pathosystem. Results from one microplot field study indicate that the interactions between $\mathrm{SCN}$, soil moisture, and pathogen infestation level had a significant effect on SDS severity and the pathogen level did not have a significant effect (Xing and Westphal 2006). However, another microplot field study that used different methods to infest soil and quantify inoculum found that pathogen levels in soil had a significant and positive effect on SDS severity (Westphal et al. 2014). In studies in a greenhouse, the number of macroconidia added to soil was related to SDS severity (Gongora-Canul et al. 2012; Njiti et al. 2001). These studies indicate complex associations between population levels of F. virguliforme and SDS. They also suggest that what Roy and associates stated in 1997 has remained true: "Much more information is needed on the relationship between inoculum density and SDS development" (Roy et al. 1997).

In addition, given the inconsistency often seen in the development of SDS in controlled studies and in production fields, factors other than soil moisture, temperature, $\mathrm{SCN}$, and fungal population level 
likely play important roles in SDS development. One of these may be crop debris and nutrients in the soil. Large quantities of soybean and corn crop residues are left in fields after harvest (Dalzell et al. 2013). It has long been known that plant debris can promote germination, growth, and pathogenicity of some Fusarium spp. and other fungi, and that nutritional requirements of fungi may be met by substrates released from plants (Curl and Truelove 1986; Deacon 2006; Griffin 1970). Further, Toussoun et al. (1963) reported that decomposing crop residues are an excellent source of exogenous carbon and nitrogen that influence the pathogenicity of $F$. solani $\mathrm{f}$. sp. phaseoli, which is closely related to $F$. virguliforme. Yang and Navi (2010) reported that corn and soybean residues can increase the frequency at which $F$. virguliforme can be isolated from soil; however, they did not investigate disease development. Thus, we hypothesized that crop residues could also be important factors in the development of SDS.

Another source of nutrients in soybean production fields that could potentially stimulate growth of $F$. virguliforme and development of SDS is exudates from seed and seedlings. Exudates are released from the seed and radicle during seed germination and early growth states (Nelson 1990, 2004; Schroth and Hildebrand 1964) which, as noted above, is when soybean appears most susceptible to infection by $F$. virguliforme. Griffin (1970) reported that exogenous carbon and nitrogen stimulate the germination of macroconidia of $F$. solani; however, this has not been examined for $F$. virguliforme.

The goal of this research was to gain insights into the effects of pathogen population levels, crop residues, and exudates from germinating seed on the development of SDS and growth of $F$. virguliforme. Three objectives were addressed: (i) determine how initial soil population level of $F$. virguliforme influences root and leaf disease severity in soybean varieties with different levels of resistance to SDS, (ii) determine whether crop residues added to soil influence SDS disease severity and whether these soil amendments interact with pathogen level, and (iii) determine whether exudates collected from germinating soybean and corn seed at different time points influence growth of $F$. virguliforme. The results contribute to our understanding of the ecology of this pathogen and the factors that influence development and management of SDS.

\section{Materials and Methods}

Preparation of inoculum and crop residue substrates. Two single-spore isolates of $F$. virguliforme from Minnesota (BE1-ss1 and Wa-ss1) Malvick and Bussey 2008), one from Illinois (Mont-1), and one from Iowa (LL0082; L. Leandro) plus one isolate of $F$. solani from Minnesota were used in these studies. The identity of isolates was confirmed by partial sequencing of the translation elongation factor- $1 \alpha$ (Geiser et al. 2004). Isolates were stored in soil culture at $4^{\circ} \mathrm{C}$ prior to these studies. Subcultures were grown on $0.5 \times$ potato dextrose agar (Difco Laboratories, Inc.) in darkness at $23^{\circ} \mathrm{C}$ for 5 weeks. Suspensions of macroconidia were prepared by flooding colonies with sterile deionized water (SDW), dislodging spores with a sterile spreader, and filtering through sterile cheesecloth. Spore density was measured with a hemacytometer and adjusted to desired concentrations using SDW.

Six different plant substrates were prepared and ground in a sterile blender, as follows. Mature corn seed and soybean seed was ground to particles $\leq 3 \mathrm{~mm}$ in size. Mature soybean stems grown in a field in central Minnesota were harvested, washed, dried, and ground to fragments $<1 \mathrm{~cm}$ in length. Corn stalks ( $3 \mathrm{~cm}$ in diameter) and corn roots from vegetative plants were separated, washed, air dried, cut into pieces of $<3 \mathrm{~cm}$, and ground separately to fragments $\leq 1 \mathrm{~cm}$ in length. The ground substrate treatments were placed into Pyrex jars and autoclaved. Red sorghum seed was soaked in water for $16 \mathrm{~h}$, drained, and autoclaved.

Studies of the roles of pathogen population levels and plant substrates in SDS development. Four population levels $\left(0,10^{1}\right.$, $10^{2}$, and $10^{3}$ macroconidia/ $\mathrm{cm}^{3}$ of soil mix) of $F$. virguliforme isolate Wa-ss1 and the six plant substrate treatments described above were used. Two soybean cultivars-MN1410 (susceptible to SDS) and MN1606 (partially resistant to SDS) (Malvick and Bussey 2008) were used. All plants were grown in a 1:1 (volume) mixture of sand and Sunshine Mix LC8 (Sun Gro Horticulture). Macroconidia were mixed into the growth medium to obtain initial concentrations of $10^{1}, 10^{2}$, and $10^{3}$ conidia/ $/ \mathrm{cm}^{3}$ of soil mix, and the control inoculation treatment contained SDW in place of a spore suspension. The six substrate treatments were mixed individually at a rate of $1.5 \%$ by volume into the growth medium, and no plant materials were added to the control treatment. The experiment was set up as a factorial with all combinations of the two soybean cultivars, four pathogen population levels, and six residue treatments. Five seeds were sown per pot ( 10 by $13 \mathrm{~cm}$ deep; Belden Plastics) and amended with $10 \mathrm{~cm}^{3}$ of Osmocote 14-14-14 at planting (Scotts Miracle-Gro Co.). Pots were arranged in a randomized block design with four replications per treatment and maintained in a greenhouse at 24 and $20^{\circ} \mathrm{C}$ (day and night, respectively) with a 14-h photoperiod. Pots were watered daily to maintain moderate soil moisture. The experiment, with all treatments and replications, was repeated once.

Plants were evaluated for disease severity and biomass 15 and 50 days after inoculation (dai). Root rot symptoms on two plants per pot were evaluated 15 dai. Roots were removed and washed carefully, and root rot severity was assessed using a scale modified from Gray and Achenbach (1996), where $0=$ no root rot symptoms, $1=$ $<25 \%$ brown discoloration and no delimited lesions on roots, $2=$ brown discoloration and brown delimited lesions on 25 to $50 \%$ of root systems, 3 = root rot and brown delimited lesions on 51 to $90 \%$ of tap root and root system, and $4=>90 \%$ tap root and root system rotted or plants dead. The remaining three plants in each pot were evaluated at 50 dai for root rot severity as noted above, foliar disease severity, and fresh biomass. Foliar disease severity was assessed as the percentage of leaf area per pot exhibiting chlorosis or necrosis typical of SDS. Fresh biomass was based on total shoots and roots in each pot.

Studies on the influence of seed exudates on growth of F. virguliforme. Seed of MN1606, MN1410, AG2002, and AG2107 soybean (the latter two from Monsanto Co.), and corn hybrid G-8745 (Syngenta Co.) were used in this study. MN1606 and AG2002 have partial resistance to SDS, whereas MN1410 and AG2107 are susceptible. Seed $(1.5 \mathrm{~g})$ of each of the five types (four soybean cultivars and one corn hybrid) were surface disinfected for $5 \mathrm{~min}$ in $3 \%$ $\mathrm{H}_{2} \mathrm{O}_{2}$, rinsed twice with SDW, and transferred aseptically into each of eight sterile glass petri dishes containing sterile Whatman filter paper number 1 (GE Healthcare Bio-Sciences) and $30 \mathrm{ml}$ of SDW. The prepared dishes with seed of corn and each soybean cultivar were incubated in darkness at $23^{\circ} \mathrm{C}$. Experimental trial I included exudates collected from different plates at time points of 4, 8, 26, and $72 \mathrm{~h}$ after seed was placed in SDW, and experimental trial II included exudates collected from different plates at 2, 32, 48, and $62 \mathrm{~h}$. Two independent petri plates representing each exudate sampling time for each seed entry were prepared for each experimental trial. Exudate samples were collected from two different petri dishes for each of the four time points for each of the four soybean cultivars and the corn per experiment with a sterile $21 \mathrm{G}$ needle (Becton Dickinson and Co.) and syringe (this equaled 40 different exudate samples in each of the two experimental trials). Exudates were then sterilized with a $0.45-\mu \mathrm{m}$ filter (MF-Millipore Membrane). Suspensions of conidia from four isolates of $F$. virguliforme and one isolate of $F$. solani were prepared as described above and adjusted to 110 conidia/ml with SDW.

For each seed exudate sample collected at each time point (40 seed exudate samples/experiment), $90 \mu \mathrm{l}$ was transferred into individual wells of 96-well plain MicroPlates with lids (Biolog, Inc.). The $F$. virguliforme conidial suspensions $(90 \mu \mathrm{l})$ were then added to each well containing the exudates. One isolate was used per MicroPlate. Mock-inoculated controls contained SDW in place of spore suspensions. Two replicates per experiment were conducted in 96-well plates using a split-plot arrangement. Isolates were main plots, exudate treatments were subplots, and experimental units were wells. The microplates were incubated in darkness at $23^{\circ} \mathrm{C}$ for 5 days, and optical density (OD) of each well was determined with a Synergy H1 Reader (Gen 5 software, version 2.00.18) at a wavelength of $670 \mathrm{~nm}$ to measure fungal density. The experiment was repeated once. 
Statistical analysis. Data from the greenhouse studies were analyzed using the liner mixed-effects model in R (3.3.0; The R Foundation for Statistical Computing). Experimental trial was treated as a random effect to characterize variation due to trial differences, and both trials were combined for analysis. Cultivar, pathogen population level, and crop residue substrate were treated as fixed effects. Root rot severity values were converted to midpoint percentage values prior to analysis. The modcompKR procedure was used to apply the Kenward-Roger approximation to the disease severity data and the biomass data to estimate the degrees of freedom and assign $P$ values to the treatments to detect differences among fixed effects and their interactions. Post hoc analysis was performed using Dunnett's test for the unilateral comparison of each population-substrate interaction treatment mean to its control $(\alpha=0.05)$.

For the seed exudate study, data were analyzed using a mixed linear model in R. The random effects of variability in the mixed linear model were based on the different microplate dishes, columns, and rows. The dish effects compensated for variability of exudates among preparation dishes, and column and row effects compensated for potential random variability in spore counts per microplate well. The fixed effect of variety-time was treated as a single variable, and data were log-transformed before analyses. The mean OD readings of inoculated water control treatments at $0 \mathrm{~h}$ were used as the baseline to determine whether growth was significantly different among exudate treatments based on linear hypothesis tests and regression analysis using a 90\% confidence interval. A Holm-Bonferroni correction was applied to pairwise comparisons to control type I error. Pairwise linear $t$ tests were performed on all data points to determine whether the mean OD measures of mycelial growth differed significantly among seed varieties at the sampling time points during germination $(P \leq 0.05)$.

\section{Results}

Influence of population levels of $\boldsymbol{F}$. virguliforme and crop residue substrates on severity of SDS. The soil population level of $F$. virguliforme, crop substrate amendments, and their interactions strongly influenced severity of SDS root and leaf disease symptoms (Table 1; Figs. 1 to 3 ). The crop substrates added to the soil medium interacted and influenced development of SDS at all pathogen levels $>0$ (Table 1; Figs. 1 to 3 ). Root rot 15 dai and foliar symptoms of SDS at 50 dai either did not develop or developed to negligible levels $(<10 \%)$ for both soybean cultivars when no plant substrates were added to the plant growth medium (Figs. 1 to 3 ). With the strong interactions between population level and crop substrate, disease development in response to pathogen population level differed among substrates (Table 1; Figs. 1 and 2). Susceptible MN1410 and resistant MN1606 had significant and different responses to the treatments for foliar disease severity and biomass (Table 1; Figs. 2 and 3). However, root rot severity was similar between the two cultivars (Table 1; Figs. 1 and 3).
Root rot developed at all pathogen population levels $>0$ for both the susceptible and partially resistant cultivars (Figs. 1 and 3). Root rot severity 15 and 50 dai was correlated positively with population levels of $F$. virguliforme and by significant interactions between population level and crop substrate (Table 1; Figs. 1 and 3). Minor root discoloration developed on roots when sterile, noninfested sorghum seed was added to soil medium. Ground soybean seed added to noninfested soil resulted in severe root discoloration in both experiments and was not included in the analysis (data not shown). Root rot severity 50 dai was generally greater with the corn and sorghum seed treatments than the other crop substrate treatments at all inoculum levels (Table 1; Fig. 1).

Foliar disease severity responded significantly to interactions between pathogen populations and crop residues (Figs. 2 and 3). No foliar disease symptoms developed on either cultivar when $F$. virguliforme was not added to the soil. Foliar disease severity for susceptible MN1410 was correlated positively with the pathogen level; however, foliar severity for partially resistant MN1610 was poorly correlated to pathogen level (Figs. 2 and 3). Foliar disease severity for MN1606 was lower than for MN1410 and not consistently related to early or late root rot (Figs. 1 to 3). Foliar symptoms were more severe ( $\geq 40 \%$ symptomatic leaf area) with the sorghum seed treatment compared with the no-substrate control on both cultivars at all population levels. Only MN1410 expressed foliar disease severity greater than $20 \%$ with the corn root and stalk and soybean stem residue treatments (Fig. 3). Whole-plant biomass loss compared with the control (none) was negatively correlated to pathogen level for both cultivars, and there was a strong interaction between pathogen level and crop substrate on biomass (Figs. 2 and 3).

The various crop substrates had significantly different interacting effects with pathogen population level on development of root rot 15 and 50 dai, foliar disease severity, and plant biomass (Table 1; Figs. 1 to 3). The highest root and leaf disease severity developed with the sorghum seed and ground corn seed treatments (Figs. 1 to 3 ). At the lowest pathogen level of $10^{1}$ conidia $/ \mathrm{cm}^{3}$ of soil, notable levels of root disease severity at 15 dai and foliar disease at 50 dai developed for both MN1410 and MN1606 with the sorghum seed amendments (Figs. 1 and 2). At that lowest pathogen level, ground corn seed was the only other substrate treatment that consistently resulted in detectable root rot 15 dai and foliar symptoms. At the pathogen level of $10^{2}$ conidia/ $/ \mathrm{cm}^{3}$, foliar and root disease severity 15 dai at levels $>20 \%$ developed for both the susceptible and resistant cultivars only with the corn seed and sorghum seed amendments (Figs. 1 and 2). At the highest pathogen level of $10^{3}$ conidia/ $\mathrm{cm}^{3}$, root rot severity 15 dai or foliar disease severity at 50 dai on the two cultivars was $>20 \%$ with the soybean stem and corn as well as the sorghum and corn seed substrates (Figs. 1 and 2). The sorghum seed amendment resulted in the most consistent positive association between early root infection and pathogen population.

Table 1. Analysis of variance of sudden death syndrome root and leaf disease severity and biomass of soybean plants exposed to different population levels of Fusarium virguliforme and different crop residue treatments in two replicated greenhouse experiments ${ }^{\mathrm{r}}$

\begin{tabular}{|c|c|c|c|c|c|}
\hline Fixed effects & $d^{\mathbf{s}}$ & Root $15^{t}$ & Root 50 & Foliar ${ }^{\mathbf{v}}$ & Biomass $^{w}$ \\
\hline Cultivar $^{\mathrm{x}}$ & 1,85 & 0.79 & 0.57 & $3.81 \mathrm{e}-04$ & $4.59 \mathrm{e}-03$ \\
\hline Population ${ }^{y}$ & 3,85 & $5.09 \mathrm{e}-14$ & $<2.2 \mathrm{e}-16$ & $3.15 \mathrm{e}-06$ & $1.53 \mathrm{e}-10$ \\
\hline Substrate $^{z}$ & 5,85 & $3.26 \mathrm{e}-16$ & $6.58 \mathrm{e}-14$ & $1.97 \mathrm{e}-11$ & $5.58 \mathrm{e}-13$ \\
\hline Cultivar $\times$ population & 3,62 & 0.84 & 0.88 & 0.01 & 0.58 \\
\hline Cultivar $\times$ substrate & 5,62 & 0.85 & 0.8951 & 0.06 & 0.57 \\
\hline Population $\times$ substrate & 15,62 & $2.97 \mathrm{e}-15$ & $2.84 \mathrm{e}-4$ & $1.75 \mathrm{e}-03$ & $1.11 \mathrm{e}-04$ \\
\hline Cultivar $\times$ population $\times$ substrate & 15,47 & 1 & 0.99 & 0.71 & 0.99 \\
\hline
\end{tabular}

${ }^{\mathrm{r}} P$ values are shown for main and interactive effects of soybean cultivar, population level of $F$. virguliforme, crop residue treatments on root rot severity 15 and 50 days after inoculation (dai), foliar disease severity, and plant biomass.

s Degrees of freedom.

t Analysis based on average root severity assessment at 15 dai.

u Analysis based on average root severity assessment at 50 dai.

$\checkmark$ Analysis based on percentage of leaflets per pot with SDS symptoms at 50 dai.

${ }^{\mathrm{w}}$ Analysis based on fresh biomass (root and shoot) per pot measured in grams at 50 dai.

$x$ Two soybean cultivars were included in this study (MN1410 and MN1606).

${ }^{y}$ Four population levels of Fusarium virguliforme $\left(0,10^{1}, 10^{2}\right.$, and $10^{3}$ macroconidia/ $\left./ \mathrm{cm}^{3}\right)$ mixed into growth medium.

${ }^{\mathrm{z}}$ Six types of substrate (none, corn root, corn stalk, soybean stem, corn seed, and sorghum seed) mixed into growth medium. 


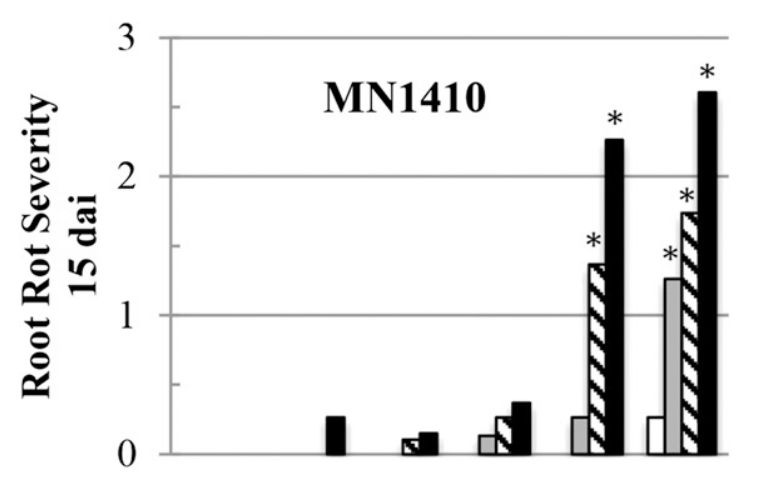

$\square \mathrm{a}$
$\square \mathrm{b}$
$\nabla_{\mathrm{c}}$
$\mathbf{- d}$
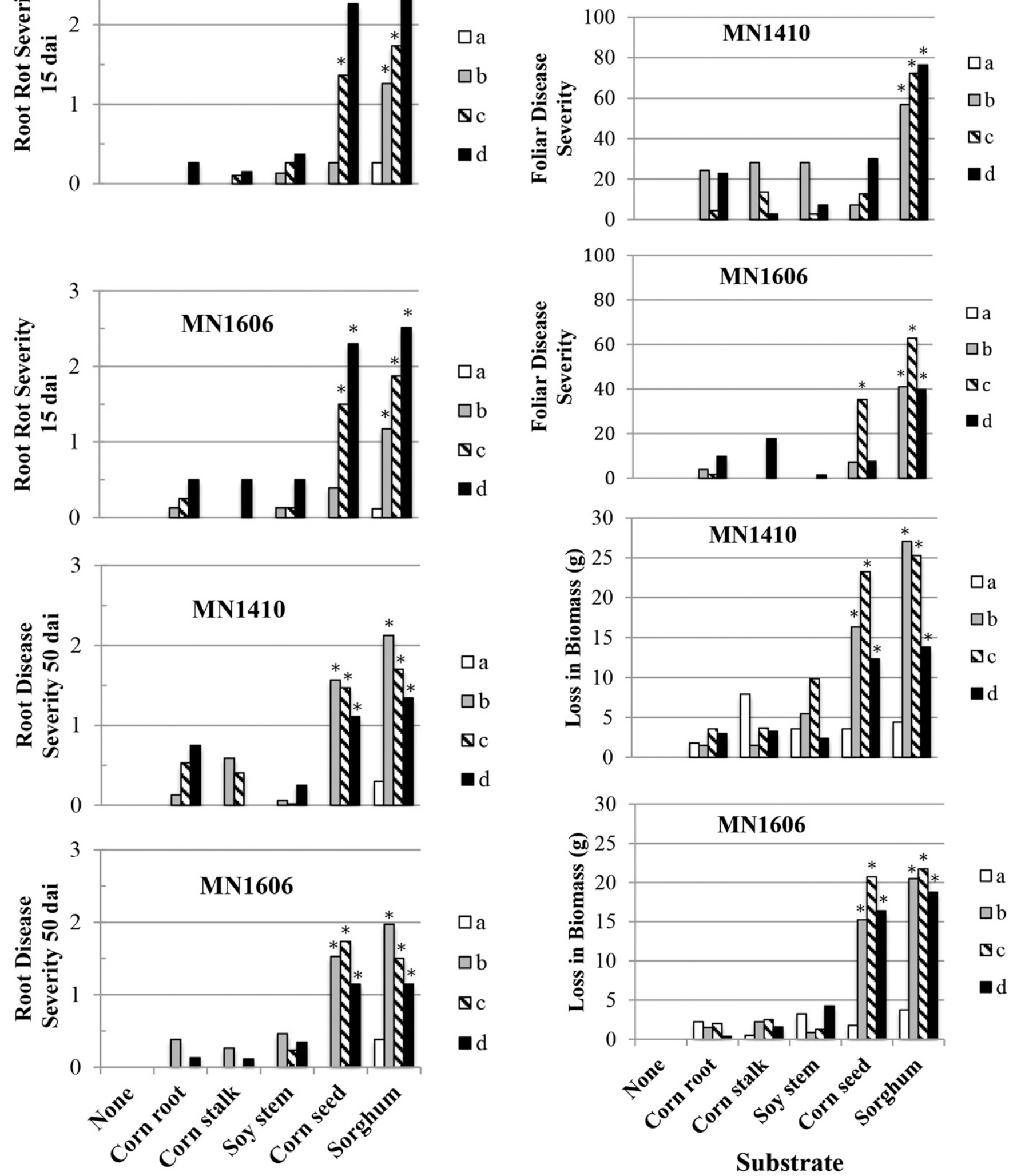

\section{Substrate}

Fig. 1. Mean differences in root rot disease severity 15 and 50 days after inoculation for susceptible (MN1410) and moderately resistant (MN1606) soybean cultivars in response to all combinations of six soil crop substrate amendments and four soil population levels of Fusarium virguliforme $\left(a=0, b=10^{1}, c=10^{2}\right.$, and $d=10^{3}$ macroconidia/ $\left.\mathrm{cm}^{3}\right)$. Values represent interactions and mean differences compared with the controls (none), and those marked with an asterisk $\left({ }^{*}\right)$ are significantly different than the control $(\alpha=0.05)$. 

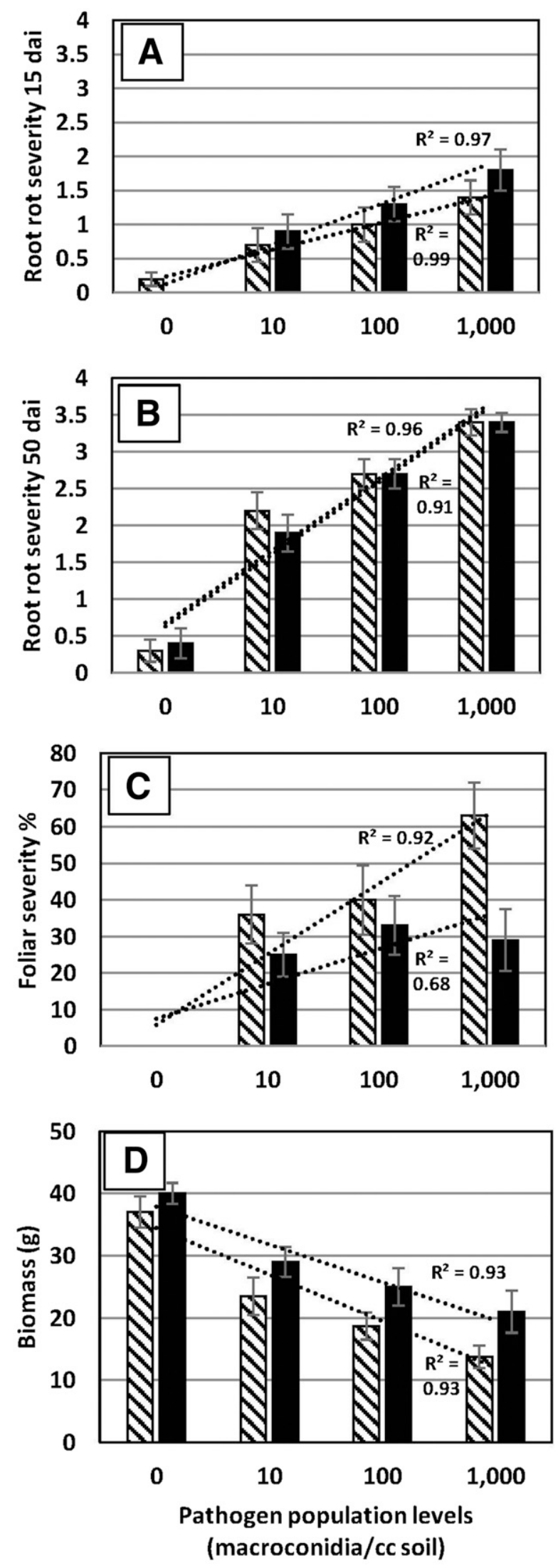

Fig. 3. Root and foliar sudden death syndrome (SDS) severity and plant biomass for soybean MN1410 (susceptible to SDS, patterned bars) and MN1606 (partially resistant to SDS, black bars) in response to four soil population levels of Fusarium virguliforme. Data were combined for five crop substrate amendments. The results represent mean root rot severity $\mathbf{A}, 15$ and $\mathbf{B}, 50$ days after inoculation (dai), C, foliar disease severity 50 dai, and $\mathbf{D}$, whole-plant biomass 50 dai in replicated greenhouse trials. The root disease rating scale ranged from $0=$ healthy to $4=$ severely diseased. Vertical lines represent standard error of the means.
Influence of seed exudates on growth of $F$. virguliforme. Soybean seed exudates collected at different times during seed germination and early seedling growth differentially influenced the growth of $F$. virguliforme and $F$. solani (Table 2 ; Fig. 4 ). The growth response of the four isolates of $F$. virguliforme and one isolate of $F$. solani were similar over all exudate treatments examined in this study (Fig. 4). Radicles began to emerge from all cultivars later than $26 \mathrm{~h}$ after immersion of seed in water, and emergence was complete by $48 \mathrm{~h}$ for all seed tested. Lengths of the radicles at the final time point in the sampling series for the different soybean cultivars were 1.2 to $3.5 \mathrm{~cm}$ in experimental trial I and 0.7 to $4.5 \mathrm{~cm}$ in trial II. The fungal growth was greatest in the exudates from the MN1606 and MN1410 seed at the time of radicle emergence, which was at the 26- and 32-h time points. The fungal isolates exhibited the greatest response to the seed exudates of MN1606, which resulted in significantly greater $(P<0.001)$ growth than other exudate samples at a time point of $\geq 26 \mathrm{~h}$ (Table 2; Fig. 4). The effects of exudates from AG2107 and AG2002 soybean on growth of $F$. virguliforme were similar to MN1410 (data not shown). Corn exudates stimulated growth of $F$. virguliforme and $F$. solani (OD range of 0.04 to 0.19 ) similar to soybean, and continued to stimulate growth as the radicle grew during the final 62- to 72-h time points (data not shown).

\section{Discussion}

Multiple factors, some known and others unknown, influence the development of SDS in soybean production fields. This study provides insights into the potential roles of crop-derived nutrient sources and the population level of $F$. virguliforme on the development of SDS in susceptible and moderately resistant soybean cultivars. Furthermore, strong interactions between these two factors suggested that crop residues from corn and soybean may be important for development of SDS, especially when the population level of $F$. virguliforme is low in field soils. Thus, this work provides new perspectives regarding the potential influence, interactions, and importance of crop residues and pathogen populations on development of SDS. These factors have implications related to assessing risk and managing this important disease.

SDS root disease severity for both cultivars, and leaf disease severity for the susceptible soybean cultivar, consistently increased with greater initial population levels of $F$. virguliforme in the soil medium where plants were grown. The range of spore concentrations in soil of $F$. virguliforme used in this study were similar to those reported previously from field and greenhouse studies (Gongora-Canul et al. 2012; Njiti et al. 2001; Rupe et al. 1997; Xing and Westphal 2009). These results expand on previous work that suggested that the inoculum dose of $F$. virguliforme can relate to the severity of SDS (Gongora-Canul and Leandro 2011; Gongora-Canul et al. 2012; Gray and Achenbach 1996; Luckew et al. 2012; Njiti et al. 2001; Rupe et al. 1997; Westphal et al. 2014). The fact that disease severity assessed at different times and with different methods in this study responded differentially to the varying pathogen levels provides further insights into disease development and mechanisms of resistance. For example, root rot severity increased at the early and late time points and plant biomass decreased in relation to the initial pathogen population in both the susceptible and partially resistant cultivars. However, partially resistant MN1606 consistently displayed lower foliar symptom severity regardless of pathogen population. These results suggest that resistance to SDS in these two cultivars acts primarily to reduce foliar disease severity rather than root rot or loss of biomass; this may indicate that different genes control resistance to root and leaf disease development, as reported by Kazi et al. (2008).

This study demonstrated the role of pathogen population level on SDS and revealed the important and interacting roles that crop residues and nutrients can potentially have in development of SDS. Two sources of nutrients in soil were studied that are likely to be available to $F$. virguliforme during early seedling growth, when plants appear to be most prone to infection (Gongora-Canul and Leandro 2011; Navi and Yang. 2008). One source was crop residues in the form of seed, root, and stem tissues that are typically left after harvest in 
soybean-corn rotations, and the other source was exudates from germinating seed. Both soybean and corn crop residues enhanced development of SDS, probably through addition of exogenous nutrients to soil. Although this has not been investigated previously in this pathosystem, these results generally agree with Toussoun et al. (1963), who reported that decomposing crop residues provide carbon and nitrogen that can influence pathogenicity of $F$. solani $\mathrm{f}$. sp. phaseoli, which is closely related to $F$. virguliforme.
Two interrelated results from this work may be especially important. One was that plants grown with no added crop residues exhibited low to no SDS in the presence of significant population levels of $F$. virguliforme, suggesting that crop residues can have a critical role in disease development. Another outcome was the strong interaction detected between different types of crop residues and population levels on root and leaf disease development. For example, a lower pathogen population was required for similar levels of disease development when

Table 2. Mean growth response for Fusarium virguliforme isolates Mont-1A and Wa1-ss1 and F. solani isolate 07-064 to exudates collected at different times (T) during seed germination from one soybean cultivar (C) partially resistant to sudden death syndrome (SDS) (MN1606) and another cultivar susceptible to SDS $(\mathrm{MN} 1410)^{\mathrm{w}}$

\begin{tabular}{|c|c|c|c|c|c|c|c|c|c|}
\hline \multirow[b]{2}{*}{$\mathbf{C} \times \mathbf{T}$} & \multicolumn{3}{|c|}{ Wa1-ss1 } & \multicolumn{3}{|c|}{ Mont1(A) } & \multicolumn{3}{|c|}{ 07-064 } \\
\hline & Estimate $^{\mathrm{x}}$ & $\mathbf{C}^{\mathbf{y}}$ & $\mathbf{T}^{\mathbf{z}}$ & Estimate $^{\mathrm{x}}$ & $\mathbf{C}^{\mathbf{y}}$ & $\mathbf{T}^{\mathbf{z}}$ & Estimate $^{\mathrm{x}}$ & $\mathbf{C}^{\mathbf{y}}$ & $\mathbf{T}^{\mathbf{z}}$ \\
\hline Inoculate $\mathrm{I}$ and $0 \mathrm{~h}$ & 0.11 & $\ldots$ & $\ldots$ & 0.10 & $\ldots$ & $\ldots$ & 0.07 & $\ldots$ & $\ldots$ \\
\hline Inoculate II & 0.27 & $\ldots$ & $\ldots$ & 0.13 & $\ldots$ & $\ldots$ & 0.02 & $\ldots$ & $\ldots$ \\
\hline MN1410 $\times 2 h$ & 0.08 & $\mathrm{a}$ & $\mathrm{a}$ & 0.11 & $\mathrm{a}$ & $\mathrm{a}$ & 0.11 & $\mathrm{a}$ & $\mathrm{a}$ \\
\hline MN1410 × 4 h & 0.14 & $a b$ & $\mathrm{a}$ & 0.10 & $\mathrm{ab}$ & $\mathrm{a}$ & 0.12 & $\mathrm{ab}$ & $\mathrm{a}$ \\
\hline MN11410 $\times 8$ h & 0.14 & $a b$ & $\mathrm{a}$ & 0.13 & $\mathrm{a}$ & $\mathrm{a}$ & 0.15 & $a b$ & $\mathrm{a}$ \\
\hline MN1410 × $26 \mathrm{~h}$ & 0.27 & $\mathrm{~b}$ & $\mathrm{~b}$ & 0.27 & c & $\mathrm{b}$ & 0.24 & c & $\mathrm{a}$ \\
\hline MN1410 $\times 32 \mathrm{~h}$ & 0.24 & $\mathrm{~b}$ & $\mathrm{bc}$ & 0.25 & bc & $\mathrm{bc}$ & 0.22 & bc & $\mathrm{a}$ \\
\hline MN1410 $\times 48 \mathrm{~h}$ & 0.18 & $a b$ & $a b$ & 0.21 & $a b c$ & $\mathrm{a}$ & 0.21 & $\mathrm{bc}$ & $\mathrm{a}$ \\
\hline $\mathrm{MN} 1410 \times 62 \mathrm{~h}$ & 0.21 & $a b$ & $\mathrm{a}$ & 0.18 & $a b c$ & $\mathrm{a}$ & 0.19 & $a b c$ & $\mathrm{a}$ \\
\hline $\mathrm{MN} 1410 \times 72 \mathrm{~h}$ & 0.17 & $a b$ & $a b$ & 0.18 & $a b c$ & $a b$ & 0.13 & $a b$ & $a b$ \\
\hline MN1606 $\times 2 h$ & 0.10 & $\mathrm{a}$ & $\mathrm{a}$ & 0.13 & $\mathrm{ab}$ & $\mathrm{a}$ & 0.14 & a & $a b$ \\
\hline MN1606 $\times 4 h$ & 0.07 & $\mathrm{a}$ & $\mathrm{a}$ & 0.08 & $\mathrm{a}$ & $\mathrm{a}$ & 0.11 & $\mathrm{a}$ & $\mathrm{a}$ \\
\hline MN1606 $\times 8 \mathrm{~h}$ & 0.16 & $\mathrm{ab}$ & $\mathrm{a}$ & 0.14 & $\mathrm{ab}$ & $\mathrm{a}$ & 0.15 & $\mathrm{a}$ & $\mathrm{a}$ \\
\hline MN1606 $\times 26 h$ & 0.51 & $\mathrm{c}$ & $\mathrm{c}$ & 0.53 & $\mathrm{c}$ & $\mathrm{c}$ & 0.40 & $\mathrm{~b}$ & $\mathrm{~b}$ \\
\hline MN1606 × $32 \mathrm{~h}$ & 0.35 & d & $\mathrm{c}$ & 0.35 & d & $\mathrm{c}$ & 0.34 & $\mathrm{~b}$ & $\mathrm{~b}$ \\
\hline MN1606 $\times 48 \mathrm{~h}$ & 0.21 & abd & $\mathrm{b}$ & 0.21 & abe & $\mathrm{a}$ & 0.18 & $\mathrm{a}$ & $\mathrm{a}$ \\
\hline MN1606 $\times 62 \mathrm{~h}$ & 0.22 & abd & $\mathrm{a}$ & 0.23 & bde & $\mathrm{a}$ & 0.20 & $\mathrm{a}$ & $\mathrm{a}$ \\
\hline MN1606 × $72 \mathrm{~h}$ & 0.27 & bd & $\mathrm{b}$ & 0.29 & de & $\mathrm{b}$ & 0.18 & $\mathrm{a}$ & $\mathrm{b}$ \\
\hline
\end{tabular}

w Fungal growth was measured based on optical density.

${ }^{\mathrm{x}}$ Estimate reports mean difference of fungal growth in exudates at each fixed effects variable $(\mathrm{C} \times \mathrm{T})$ compared with water at $0 \mathrm{~h}$ within each soybean cultivar $(\mathrm{C})$ and within each seed exudate collection time (T).

${ }^{y} \mathrm{C}$ reports independent contrasts within each soybean cultivar for every $\mathrm{C} \times \mathrm{T}$ tested. The same letters within a column are not significantly different from each other $(\alpha=0.05)$

$\mathrm{z}$ T reports independent contrasts for each seed exudate collection time for every $\mathrm{C} \times \mathrm{T}$ tested. The same letters within a column are not significantly different from each other $(\alpha=0.05)$.
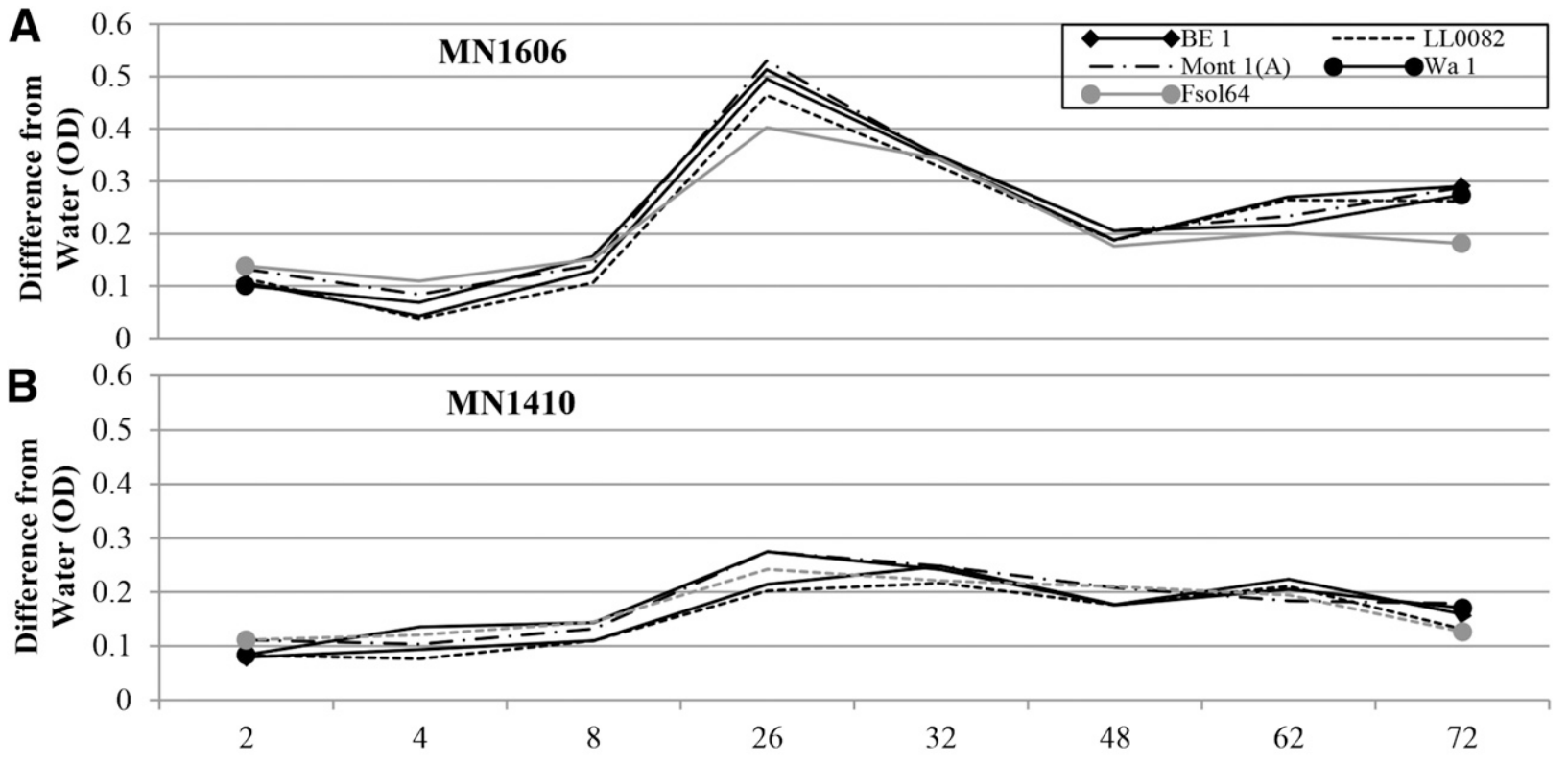

Exudate Collection Time (hrs)

Fig. 4. Growth response for four isolates of Fusarium virguliforme (BE 1, Mont 1(A), LL0082, and Wa1-ss1) and one isolate of $F$. solani (Fsol64) to seed exudates collected at time points from 2 to $72 \mathrm{~h}$ during germination from a soybean cultivar partially resistant to sudden death syndrome (SDS) (MN1606) and another cultivar susceptible to SDS (MN1410). Fungal growth in exudate solutions was measured as optical density (OD) and reported as the difference at each time point compared with water at $0 \mathrm{~h}$. 
the source of exogenous nutrients was nutrient-rich seed rather than relatively nutrient-poor stems, roots, and stalks. It may be important to consider that these effects were noted in this study with a sand/ potting soil mixture, and repeating some of this work with other soil types may help to clarify how the results compare in other soil environments.

Exudates from germinating seed stimulated growth of $F$. virguliforme, and could also be important for root infection. Exudates released into the spermosphere during seed germination are composed of nutrient-rich solutes that had been shown previously to influence the behavior of F. solani f. sp. phaseoli (Nelson 2004; Weitbrecht et al. 2011). To our knowledge, this had not been previously investigated with $F$. virguliforme. The spatial and temporal dynamics in the release of seed exudates may be especially important for the SDS pathosystem because infection in early soybean growth stages is most conducive to the development of high foliar symptom severity (Gongora-Canul and Leandro 2011; Navi and Yang 2008). Thus, exudates released during radicle emergence when infection is most likely to lead to severe foliar SDS disease development could influence fungal growth and infection.

Most of the seed exudates tested from the different crops and cultivars and collected at different times during germination and early seedling growth had similar positive effects on growth of $F$. virguliforme. However, a notable exception was the exudate sample produced during radicle emergence from the partially resistant MN1606, which promoted significantly more growth than the other exudates collected in this study. We had hypothesized that exudates from susceptible soybean cultivars might provide more stimulus for growth of $F$. virguliforme than partially resistant varieties. This research, however, did not support this hypothesis or establish an association between different levels of reported resistance to SDS and the influence of their seed exudates on growth of the pathogen. Thus, foliar resistance ratings to SDS appear to not correspond to the effect a soybean cultivar has on the stimulation of $F$. virguliforme spore germination and growth. MN1606 appears to be efficient at reducing the effects of the fungal toxins on leaf damage rather than preventing root infection. Seed exudates from corn, an asymptomatic host for $F$. virguliforme (Kolander et al. 2012), also promoted growth of this pathogen similar to seed exudates of most of the soybean cultivars tested. Although seed and seedling exudates stimulated growth of $F$. virguliforme, it remains to be determined how they and their chemical components produced at different time points influence infection of soybean roots by $F$. virguliforme. The fact that the crop residues in soil had such a strong effect on disease development, in spite of the likely concomitant presence of seed or seedling exudates, could suggest that exudates may have a relatively small role in supplying nutrients to $F$. virguliforme that aid its infection of soybean when other nutrient sources are available.

In summary, this work demonstrates and provides insight into the roles that soil population levels of $F$. virguliforme, crop residues, and seed exudates can have on development of SDS and growth of the pathogen. These factors likely also interact with others associated with SDS such as soil moisture, temperature, SCN, and coinfection by other pathogens that occur with SDS (Hartman et al. 2015 a,b; Malvick et al. 2003). Corn and soybean residues, which are common in fields with corn-soybean rotations, likely provide exogenous nutrients that can enhance the efficacy of inoculum, especially at low levels, and thus increase the risk of an SDS outbreak. Pathogen population level is also likely a critical and measurable factor that influences risk and development of SDS. The significance of these findings is based on the insights they provide into the etiology of SDS and their possible implications to SDS management and risk assessment. For example, reducing the quantity of crop residues left behind in fields after harvest by improving harvest efficiency and so on may help to reduce risk of SDS, as was also suggested by Yang and Navi (2010). Further, given that robust quantitative polymerase chain reaction methods have been developed for quantification of $F$. virguliforme in soil (Kandel et al. 2015), it may be feasible and valuable to measure populations of this pathogen in soil and use this information to assess risk of SDS and to inform disease management decisions in conjunction with other factors.

\section{Acknowledgments}

Support for this study was provided by the North Central Soybean Research Program, the Minnesota Soybean Research and Promotion Council, and the University of Minnesota Agricultural Experiment Station. We thank J. Orf at the University of Minnesota for providing seed of MN1410 and MN1606 soybean and L. Leandro from Iowa State University for providing an isolate of $F$. virguliforme from Iowa.

\section{Literature Cited}

Aoki, T., O’Donnell, K., Homma, Y., and Lattanzi, A. R. 2003. Sudden death syndrome of soybean is caused by two morphologically and phylogenetically distinct species within the Fusarium solani species complex: F. virguliforme in North America and F. tucumaniae in South America. Mycologia 95:660-684.

Chang, H., Domier, L. L., Radwan, O., Yendrek, C. R., Hudson, M. E., and Hartman, G. L. 2016. Identification of multiple phytotoxins produced by Fusarium virguliforme including a phytotoxic effector (FvNIS1) associated with sudden death syndrome foliar symptoms. Mol. Plant-Microbe Interact. 29:96-108.

Curl, E. A., and Truelove, B. 1986. The Rhizosphere. Springer-Verlag, Berlin, Heidelberg, Germany. doi:10.1007/978-3-642-70722-3

Dalzell, B. J., Johnson, J. M., Tallaksen, J., Allan, D. L., and Barbour, N. W. 2013. Simulated impacts of crop residue removal and tillage on soil organic matter maintenance. Soil Sci. Soc. Am. J. 77:1349-1356.

Deacon, J. 2006. Fungal Biology, 4th ed. Blackwell Publishing Ltd., Oxford.

de Farias Neto, A. L., Hartman, G. L., Pedersen, W. L., Li, S., Bollero, G. A., and Diers, B. W. 2006. Irrigation and inoculation treatments that increase the severity of soybean sudden death syndrome in the field. Crop Sci. 46: 2547-2554.

Geiser, D. M., Jiménez-Gasco, M. d. M., Kang, S., Makalowska, I., Veeraraghavan, N., Ward, T. J., Zhang, N., Kuldau, G. A., and O'Donnell, K. 2004. FUSARIUM-ID v. 1.0: A DNA sequence database for identifying Fusarium. Eur. J. Plant Pathol. 110:473-479.

Gongora-Canul, C., and Leandro, L. F. S. 2011. Plant age affects root infection and development of foliar symptoms of soybean sudden death syndrome. Plant Dis. 95:242-247.

Gongora-Canul, C., Nutter, F. W., Jr., and Leandro, L. F. S. 2012. Temporal dynamics of root and foliar severity of soybean sudden death syndrome at different inoculum densities. Eur. J. Plant Pathol. 132:71-79.

Gray, L. E., and Achenbach, L. A. 1996. Severity of foliar symptoms and root and crown rot of soybean inoculated with various isolates and inoculum rates of Fusarium solani. Plant Dis. 80:1197-1199.

Griffin, G. J. 1970. Carbon and nitrogen requirements for macroconidial germination of Fusarium solani: Dependence on conidial density. Can. J. Microbiol. 16:733-740.

Hartman, G. L., Chang, H.-X., and Leandro, L. F. 2015a. Research advances and management of soybean sudden death syndrome. Crop Prot. 73:60-66.

Hartman, G. L., Leandro, L. F., and Rupe, J. C. 2015b. Sudden death syndrome. Pages 88-90 in: Compendium of Soybean Diseases, 5th ed. G. Hartman, J. Rupe, L. Domier, E. Sikora, K. Steffey, and J. Davis, eds. American Phytopathological Society, St. Paul, MN.

Jin, H., Hartman, G. L., Nickell, C. D., and Widholm, J. M. 1996. Phytotoxicity of culture filtrates from Fusarium solani, the causal agent of sudden death syndrome of soybean. Plant Dis. 80:922-927.

Kandel, Y. R., Haudenshield, J. S., Srour, A. Y., Islam, K. T., Fakhoury, A. M., Santos, P., Wang, J., Chilvers, M. I., Hartman, G. L., Malvick, D. K., Floyd, C. M., Mueller, D. S., and Leandro, L. F. S. 2015. Multilaboratory comparison of quantitative PCR assays for detection and quantification of Fusarium virguliforme from soybean roots and soil. Phytopathology 105: 1601-1611.

Kazi, S., Shultz, J., Afzal, J., Johnson, J., Njiti, V. N., and Lightfoot, D. A. 2008. Separate loci underlie resistance to root infection and leaf scorch during soybean sudden death syndrome. Theor. Appl. Genet. 116:967-977.

Kolander, T. M., Bienapfl, J. E., Kurle, J. E., and Malvick, D. K. 2012 Symptomatic and asymptomatic host range of Fusarium virguliforme, the causal agent of soybean sudden death syndrome. Plant Dis. 96:1148-1153.

Lersten, N. R., and Carlson, J. B. 2004. Vegetative morphology. Pages 31-35 in: Soybeans: Improvement, Production, and Uses, 3rd ed. H. R. Boerma and J. E. Specht, eds. American Society of Agronomy, Inc., Madison, WI.

Luckew, A. S, Cianzio, S. R., and Leandro, L. F. 2012. Screening method for distinguishing soybean resistance to Fusarium virguliforme in resistant $\times$ resistant crosses. Crop Sci. 52:2215-2223.

Malvick, D. K., and Bussey, K. E. 2008. Comparative analysis and characterization of the soybean sudden death syndrome pathogen Fusarium virguliforme in the northern United States. Can. J. Plant Pathol. 30:467-476.

Malvick, D. K., Chen, W., Kurle, J. E., and Grau, C. R. 2003. Cultivar preference and genotype distribution of the brown stem rot pathogen Phialophora gregata in the Midwestern United States. Plant Dis. 87:1250-1254.

Navi, S. S., and Yang, X. B. 2008. Foliar symptom expression in association with early infection and xylem colonization by Fusarium virguliforme (formerly $F$. solani $\mathrm{f}$. sp. glycines), the causal agent of soybean sudden death syndrome. Online publication. Plant Health Prog. doi:10.1094/ PHP-2008-0222-01-RS 
Nelson, E. B. 1990. Exudate molecules initiating fungal responses to seed and roots. Plant Soil 129:61-73.

Nelson, E. B. 2004. Microbial dynamics and interactions in the spermosphere. Annu. Rev. Phytopathol. 42:271-309.

Njiti, V. N., Johnson, J. E., Torto, T. A., Gray, L. E., and Lightfoot, D. A. 2001. Inoculum rate influences selection for field resistance to soybean sudden death syndrome in the greenhouse. Crop Sci. 41:1726-1731.

O’Donnell, K., Sink, S., Scandiani, M. M., Luque, A., Colletto, A., Biasoli, M., Lenzi, L., Salas, G., Gonzalez, V., Ploper, L. D., Formento, N., Pioli, R. N., Aoki, T., Yang, X. B., and Sarver, B. A. 2010. Soybean sudden death syndrome species diversity within North and South America revealed by multilocus genotyping. Phytopathology 100:58-71.

Pudake, R. N., Swaminathan, S., Sahu, B. B., Leandro, L. F., and Bhattacharyya, M. K. 2013. Investigation of the Fusarium virguliforme fvtox 1 mutants revealed that the FvTox1 toxin is involved in foliar sudden death syndrome development in soybean. Curr. Genet. 59:107-117.

Roy, K. W., Rupe, J. C., Hershman, D. E., and Abney, T. S. 1997. Sudden death syndrome of soybean. Plant Dis. 81:1100-1111.

Rupe, J. C., Robbins, R. T., and Gbur, E. E. 1997. Effect of crop rotation on soil densities of Fusarium solani and Heterodera glycines and on the development of sudden death syndrome of soybean. Crop Prot. 16:575-580.

Rupe, J. C., Sabbe, W. F., Robbins, R. T., and Gbur, E. E., Jr. 1993. Soil and plant factors associated with sudden death syndrome of soybean. J. Prod. Agric. 6:218-221.
Scherm, H., Yang, X. B., and Lundeen, P. 1998. Soil variables associated with sudden death syndrome in soybean fields in Iowa. Plant Dis. 82: 1152-1157.

Schroth, M. N., and Hildebrand, D. C. 1964. Influence of plant exudates on rootinfecting fungi. Annu. Rev. Phytopathol. 2:101-132.

Toussoun, T. A., Patrick, Z. A., and Snyder, W. C. 1963. Influence of crop residue decomposition products on the germination of Fusarium solani f. sp. phaseoli chlamydospores in soil. Nature 197:1314-1316.

Weitbrecht, K., Müller, K., and Leubner-Metzge, G. 2011. First off the mark: Early seed germination. J. Exp. Bot. 62:3289-3309.

Westphal, A., Li, C., Xing, L., McKay, A., and Malvick, D. 2014. Contributions of Fusarium virguliforme and Heterodera glycines to the disease complex of sudden death syndrome of soybean. PLoS One 9:e99529.

Xing, L., and Westphal, A. 2006. Interaction of Fusarium solani f. sp. glycines and Heterodera glycines in sudden death syndrome of soybean. Phytopathology 96 : 763-770.

Xing, L., and Westphal, A. 2009. Effects of crop rotation of soybean with corn on severity of sudden death syndrome and population densities of Heterodera glycines in naturally infested soil. Field Crops Res. 112:107-117.

Yang, X. B., and Navi, S. 2010. Good harvest in corn should help manage soybean SDS. Online publication. Iowa State University Extension and Outreach Integrated Crop Management. http://crops.extension.iastate.edu/ cropnews/2010/09/good-harvest-corn-should-help-manage-soybean-sds 